\title{
Methcyclohexyl methacrylate-methacrylate copolymers:An effective cold flow improver for the biodiesel blends
}

\author{
Mingxia Yuan ${ }^{1}$, Xin $\operatorname{Lin}^{1}$, Hualin $\operatorname{Lin}^{1}$, Yuan Xue ${ }^{1}$, and Sheng $\operatorname{Han}^{1}$ \\ ${ }^{1}$ Shanghai Institute of Technology
}

October 29, 2021

\begin{abstract}
The poor cold flow property is one of the main obstacle factors in affecting the utilization of high-proportional biodiesel blends in engines. In this study, methcyclohexyl methacrylate-methacrylate copolymers (MCHMA-R1MC, R1 = C12, C14, C16, C18) were synthesized at various molar ratios by radical polymerization and characterized by FTIR, GPC, and 1H NMR. Their structures and properties areanalyzed and characterized by FTIR, GPC, and 1H NMR. The resulting copolymers were tested as the cold flow improver in terms of cold filter plugging point (CFPP) and solid point (SP) measurement for treated and untreated B20 biodiesel blends (20 vol.\% biodiesel +80 vol.\% diesel). Results showed that the CFPP and SP of B20 decreased to a varied extent after MCHMA-R1MC treatment. When the monomer ratio of is 1:7, MCHMA-C14MC (1:7) proved the greatest depression in CFPP and SP of B20 by 18 and 25 at 2000 ppm dosage. The effects of MCHMA-R1MC copolymers on crystal behavior was studied through polarizing optical microscope(POM), differential scanning calorimetry(DSC) and viscositytemperature curves. The results indicated that MCHMA-C14MC could effectively delay the aggregation of wax crystals and change their crystalline behavior by changing the shape of the crystals and inhibiting the formation of large wax crystals, and then lower the low-temperature viscosity of biodiesel blends and make it exhibiting better cold flow properties.
\end{abstract}

Methcyclohexyl methacrylate-methacrylate copolymers:An effective cold flow improver for the biodiesel blends

\section{Mingxia Yuan ${ }^{1}$. Xin Li ${ }^{1}$. Yuan Xue ${ }^{1,3},{ }^{*}$. Hualin Lin ${ }^{1, *}$. Sheng Han ${ }^{1,2,4}$,}

${ }^{1}$ School of Chemical and Environmental Engineering, Shanghai Institute of Technology, Shanghai 201418, China

${ }^{2}$ School of Chemistry and Chemical Engineering, Shihezi University, Xinjiang, 832003, China

3 School of Materials Science and Engineering, the University of Shanghai for Science and Technology, Shanghai, 200093, China

${ }^{4}$ School of Chemical and Environmental Engineering, Sichuan University of Science \& Engineering, Sichuan, 643002, China

* Corresponding author: Fax: +86-021-60873565, Tel: +86-02160873560; Email address: hansheng654321@sina.com (Sheng Han), sit_xueyuan@163.com (Yuan Xue), lhl6534@163.com (Hualin Lin)

\section{Abstract}

The poor cold flow property is one of the main obstacle factors in affecting the utilization of high-proportional biodiesel blends in engines. In this study, methcyclohexyl methacrylate-methacrylate copolymers (MCHMA$\mathrm{R}_{1} \mathrm{MC}, \mathrm{R}_{1}=\mathrm{C}_{12}, \mathrm{C}_{14}, \mathrm{C}_{16}, \mathrm{C}_{18}$ ) were synthesized at various molar ratios by radical polymerization and characterized by FTIR, GPC, and ${ }^{1} \mathrm{H}$ NMR. Their structures and properties areanalyzed and characterized by FTIR, GPC, and ${ }^{1} \mathrm{H}$ NMR. The resulting copolymers were tested as the cold flow improver in 
terms of cold filter plugging point (CFPP) and solid point (SP) measurement for treated and untreated B20 biodiesel blends (20 vol.\% biodiesel +80 vol.\% diesel). Results showed that the CFPP and SP of B20 decreased to a varied extent after MCHMA- $\mathrm{R}_{1} \mathrm{MC}$ treatment. When the monomer ratio of is 1:7, MCHMA$\mathrm{C}_{14} \mathrm{MC}$ (1:7) proved the greatest depression in CFPP and SP of B20 by 18 and 25 at 2000 ppm dosage. The effects of MCHMA- $\mathrm{R}_{1} \mathrm{MC}$ copolymers on crystal behavior was studied through polarizing optical microscope(POM), differential scanning calorimetry(DSC) and viscosity-temperature curves. The results indicated that MCHMA- $\mathrm{C}_{14} \mathrm{MC}$ could effectively delay the aggregation of wax crystals and change their crystalline behavior by changing the shape of the crystals and inhibiting the formation of large wax crystals, and then lower the low-temperature viscosity of biodiesel blends and make it exhibiting better cold flow properties.

\section{Keywords}

biodiesel blends * cold flow improver * methcyclohexyl methacrylate-methacrylate copolymers * action mechanism

\section{Introduction}

Biodiesel is a kind of biofuel originated from renewable natural resources such as waste cooking oil, vegetable oil, and animal fat (Eryilmaz et al., 2016). As the advantages of low toxicity, no pollution, good engine aerodynamic performance, wide source of raw materials, renewable and good fuel performance (Eryilmaz and Yesilyurt, 2016; Daho et al., 2012), the biodiesel is considered as one of the best substitutes for petroleum diesel(Eryilmaz et al., 2015). For the purpose of accelerate the promotion and application of biodiesel, it was always used by blending with the petroleum diesel. And many blending policies have been issued by countries around the world

(Lim et al., 2010; Giraldo et al., 2013; Sharafutdinov et al.,2013). The European Committee for Standardization stipulated that no more than $7 \mathrm{vol} \%$ of biodiesel could be mixed into petroleum diesel, and the government of Argentine allowed the blending ratio of biodiesel to reach 20\%. Brazil plans to raise the proportion of biodiesel blending in commercial diesel fuel to $13 \%$ in march 2021. Indonesia has increased the proportion of palm oil blended with biodiesel from $10 \%$ in 2013 to $30 \%$ in 2020. Malaysian government officially launched the B20 biodiesel program, which would be fully implemented in domestic gas stations in June 2021. In China, nearly 5 million tons of waste cooking oil were derived from the urban catering industry, and these waste oils have become the major raw material source for biodiesel production. Furthermore, the government is actively promoting the use of biodiesel-diesel blends. The standard of B5 biodiesel blends (GB/T25199-2010) was published by China National Standardization Management Committee. Also, B10 and B20 are planning to be implemented and put into use. However, biodiesel is a mixture of various saturated fatty acid esters and unsaturated fatty acid esters(Giraldo et al., 2013; Rao and Chary, 2018; Toda et al., 2013). With the increase of biodiesel, more saturated fatty acid esters with high freezing points in biodiesel blends could easily crystallize and accumulation leading to the blockage of the engine (Anwar and Garforth, 2016; Magalhaes et al., 2019; Xue et al., 2016). Therefore, the poor cold flow properties of biodiesel blends is considered as the critical factors limiting the application of high proportion biodiesel blends in diesel engines, and is an urgent problem to be solved for us.

Pour point depressants (PPDs), also known as cold flow improvers (CFI), is a kind of oil additives which can improve the cold flow properties of diesel significantly just at a small dosage (Su et al., 2021; Gu et al., 2018; Wang et al., 2014; Du et al., 2013). Adding PPDs have proved to be a much simpler and more efficient way, to enhance the cold flow properties of biodiesel or biodiesel blends. It has the advantages of small dosages, simple operation, high economic benefit, high-effective, and low cost (OliveiraLize et al., 2016; Gomes et al., 2017; Xu et al., 2018). PPDs can interact with wax crystals to affect the crystallization behavior and change the crystal shape of diesel, and consequently to improve its cold flow properties (Zhou et al., 2016; Admiral et al., 2016; Mao et al., 2018; Zhou et al., 2015). Many researchers have been engaged in the exploitation of new and efficient cold flow improvers. In particular, PMA type pour point depressant, with structural diversity, show good improvement effects for diesel and biodiesel. Ma et al. (2015) did great work on the cold flow characteristics of the blend of soybean biodiesel with $0^{\#}$ diesel and methacrylate pour point depressant. 
They found that adding $1 \%$ of 10-320 PPD to B60 produced a CFPP of -10 . Moreover, PPD changes the crystal growth process and maintains the small crystal size through co-crystallization. They also showed that diesel and biodiesel have different compositions and that the two kinds of crystals precipitated together at low temperatures. The dispersion of one crystal around the other creates some repulsion between diesel and biodiesel, inhibiting aggregation and growth. Monirul et al. (2017) did a systematic and thorough work to investigate the effect of adding PMA to CB20 coconut biodiesel to improve the cold filtration performance of biodiesel. They confirmed the $0.03 \mathrm{wt} \%$ PMA has the best cold flow properties, which can reduce the PP, CP, and CFPP of CB20 by 9,3 , and 8 , respectively. They also proved that the crystal strengthening process and the wax crystal precipitation rate changed for the use of PMA. Although methacrylate has been shown to be an effective cold flow improver for biodiesel according to previous works, the reduction in CFPP is limited. Furthermore, there is a lack of clear datas in previous studies to explain the mechanism of how methacrylate affects the cold flow performance of biodiesel-diesel blends. Therefore, prepare a novel polymethacrylate polymer with simple structure and high efficiency remains a necessity.

To inquire into the effect of methacrylate on the biodeisel blends performance, the methcyclohexyl methacrylate-methacrylate copolymers (MCHMA- $\mathrm{R}_{1} \mathrm{MC}, \mathrm{R}_{1}=\mathrm{C}_{12}, \mathrm{C}_{14}, \mathrm{C}_{16}, \mathrm{C}_{18}$ ) were synthesized and used as a new kind of PPD for biodeisel blends in this work. The effects of these PPDs on B20 cold flow characteristics were studied and compared with previous reports.

Experimental

Reagents and oil samples

Methacrylic acid, cyclohexanol, p-toluene sulfonic acid (PTSA), hydroquinone, toluene, Sodium hydroxide, 1-dodecyl alcohol, 1-tetradecyl alcohol, 1-hexadecyl alcohol, 1-octadecyl alcohol and benzoyl peroxide are provided by Titan Scientific Co., Ltd (Shanghai, China). All are analytical grade and can be used without further purification.

Diesel fuel was provided by Sinopec Group (Shanghai, China). Waste cooking oil was obtained from Shanghai Zhong-qi Environment Technology Co., Ltd. (Shanghai, China). Biodiesel was prepared in the laboratory according to the previous reports (Su et al., 2021; Wang et al., 2015; Zhao et al., 2016).

Synthesis of monomers

As the Fig. 1 shows the synthesis procedure for the preparation of monomers. The $\mathrm{R}_{1} \mathrm{MC}$ was prepared through methacrylic acid in a 1.2:1 molar ratio with different n-alkyl esters $(\mathrm{n}=12,14,16$, and 18) at 120 $\operatorname{deg} \mathrm{C}$ for $6 \mathrm{~h}$ with hydroquinone as an inhibitor, PTSA was screened as the catalyst, and toluene was used as the solvent. After the reaction, the crude product was washed to neutral with $5 \% \mathrm{NaOH}$ solution and distilled water. Finally, the products were distilled in vacuum using a rotary-evaporator and dried in vacuum for $8 \mathrm{~h}$ at 55. MCHMA was synthesized by methacrylic acid and cyclohexanol under the same reaction conditions. Both end products exist in the form of a colorless liquid.

Preparation of copolymers

The polymerization process of the MCHMA- $\mathrm{R}_{1} \mathrm{MC}$ copolymer was shown in Fig. 2. In a nitrogen environment, n-alkyl methacrylate was copolymerized with methcyclohexyl methacrylate in toluene at different molar ratios (1:1, 1:3, 1:5, 1:7, and 1:9). When the reaction temperature increased to $110 \mathrm{degC}$, a toluene solution with $1 \%$ benzoyl peroxide dissolved as an initiator was added to the above system, and the reaction continues for 8 hours under continuous stirring. After the reaction, the product was washed with ethyl alcohol for 3 times and dried to obtain the final product.

Characterization of monomers and copolymers

The ${ }^{1} \mathrm{H}$ NMR spectra, FTIR spectra, and GPC spectra of those prepared monomers and copolymers were performed using AVANCE III $500 \mathrm{MHz}$ spectrometer (Switzerland), Nicolet iN10 Fourier Transform Infrared spectrometer (FTIR, (USA) were characterized by ${ }^{1} \mathrm{H}$ nuclear magnetic resonance $\left({ }^{1} \mathrm{H}\right.$ NMR) spectroscopy 
and gel permeation chromatography (GPC) (LC-8320 GPC, Japan). The detailed analysis methods and test conditions were provided in the Supporting Information.

Compositions of diesel and biodiesel

The chemical compositions of diesel and biodiesel were determined by using a gas chromatography-mass spectrometer (GC-MS, QP2010SE, Shimadzu) in this work, and the analytical results were shown Fig. S1, Table S1, and Table S2. The proportion of n-alkanes in diesel reaches up to $49.24 \mathrm{wt} . \%$. The carbon number of n-alkanes is mainly distributed in the range from C9 to C23, and the average carbon number of n-alkanes is 14. The mainly component of biodiesel are unsaturated FAMEs and saturated FAMEs, and their proportions are $61.46 \%$ and $38.42 \%$, respectively.

Properties of diesel, biodiesel, and B20

B20 was prepared by the mixture of $20 \mathrm{vol} . \%$ biodiesel and 80 vol.\% diesel. The MCHMA-R $\mathrm{MC}_{1}$ copolymers were added into B20 at 0, 500, 1000, 1500, 2000, 2500, and $3000 \mathrm{ppm}$ by weight. The treated B20 were first stirred at 40-50 and then ultrasonic dispersed for 25-30 minutes to ensure the copolymers were evenly distributed in biodiesel blends. The physicochemical characteristics of diesel, biodiesel and B20 were listed in Table 1. The cold flow properties of diesel will be measured by CFPP and SP. CFPP is the maximum temperature when the time for a $20 \mathrm{ml}$ sample to flow through the filter exceeds the 60 s under the specified conditions. The SP indicates that the diesel has a maximum temperature of the fluidity at a tilt 45 degrees. The CFPP and SP were determined according to the standards of ASTM D6371 (2017) and ASTM D5949 (2016) by the SYD-510F1 multifunctional low-temperature tester (Shanghai Chang Ji Instrument Co., Ltd., China). The measurement details of fuel specific features, such as kinematic viscosity (40 degC), flash point, density, and acid value were provided in Supporting Information. To avoid special cases, the test was repeated three times for each data point and the average value was taken.

DSC measurements

A Q-2000 differential calorimetry scanner (TA Instruments Co., Ltd., America) was used to determine the crystal precipitation temperature and liquid-solid phase change of oil samples. All the samples were measured from $0 \operatorname{deg} \mathrm{C}$ to $-25 \operatorname{deg} \mathrm{C}$ at a scanning rate of $5 \mathrm{deg} \mathrm{C} / \mathrm{min}$.

POM measurements

A DM2500P polarizing microscope (Leica Instrument Co., Ltd., Germany) was used to analyze the crystallization behavior and crystal morphology of oil samples. All the samples were measured from 20 to $-60 \mathrm{degC}$ at a cooling rate of $5 \mathrm{degC} / \mathrm{min}$. The photomicrographs of all samples were taken at 100x magnification and taken at intervals of $1 \mathrm{degC}$.

Rheological measurements

Viscosity is an important indicator of the cold flow properties of oil products and is greatly affected by temperature. In this paper, the advanced HAAKE MARS III rheometer (Germany) was used to measure the viscosity-temperature curve of the sample before and after the addition under the shear rate of $5 \mathrm{~s}^{-1}$ in the temperature range of 10 to -40 .

Results and discussion

Structural characterization of the PPDs

Fourier transform infra red spectrometer observation of the characteristics of resultant peaks. The chemical structures of the above compounds were assigned by mean of FTIR spectroscopy. The FTIR spectrum of $\mathrm{C}_{14} \mathrm{MC}$ was shown in Fig. 3a. The $\mathrm{C}=\mathrm{C}$ and $\mathrm{C}=\mathrm{O}$ stretching vibration peak were observed at 1639 and $1720 \mathrm{~cm}^{-1}$. The stretching vibration peak of $-\mathrm{C}-\mathrm{O}-\mathrm{C}-$ appeared at 1295 and $1164 \mathrm{~cm}^{-1}, 721 \mathrm{~cm}^{-1}$ was the absorption peak of $-\left(\mathrm{CH}_{2}\right)_{\mathrm{n}}-(\mathrm{n}>4)$ long-chain alkyl group. Fig. 3b showed the infrared spectrum of MCHMA. It is a characteristic peak of $\mathrm{C}=\mathrm{O}$ at $1718 \mathrm{~cm}^{-1}$, and the strong absorption peak at $-\mathrm{C}-\mathrm{O}-\mathrm{C}-$ was appeared at 1232 and $1120 \mathrm{~cm}^{-1}$. By the time, the $\mathrm{C}=\mathrm{C}$ radial vibration peak was observed at 1637 
$\mathrm{cm}^{-1}$. No strong absorption peak was detected at $3600-3200 \mathrm{~cm}^{-1}$ for the two monomers. The results show that the monomer was free of alcoholic hydroxyl group and acid hydroxyl group. Fig. 3c showed that the FTIR spectra of the MCHMA- $\mathrm{C}_{14} \mathrm{MC}$ copolymer characteristic absorption peaks of $-\mathrm{CH}_{3}$ and $-\mathrm{CH}_{2}$ were at 2925 and $2854 \mathrm{~cm}^{-1}$. The strong absorption peak of $\mathrm{C}=\mathrm{O}$ at $1730 \mathrm{~cm}^{-1}$ and tensile vibration peaks at 1240 and $1149 \mathrm{~cm}^{-1}$. $744 \mathrm{~cm}^{-1}$ and $721 \mathrm{~cm}^{-1}$ were the absorption peaks of $-(\mathrm{CH} 2) \mathrm{n}-(\mathrm{n}>4)$ long-chain alkyl groups. The characteristic $\mathrm{C}=\mathrm{C}$ peaks of MCHMA and $\mathrm{C}_{14} \mathrm{MC}$ completely disappeared which proved that the polymer synthesis was successful.

The ${ }^{1} \mathrm{H}$ NMR spectra of MCHMA was illustrated as Fig. 4a. The peaks at $1.50 \mathrm{ppm}$ and $1.85 \mathrm{ppm}$ indicate a sympathetic vibration of cyclohexyl group of cyclohexyl methacrylate. $\delta_{\mathrm{H}} 6.10$ and $5.54 \mathrm{ppm}$ were $=\mathrm{CH}_{2}$ protons resonance vibration, $\delta_{\mathrm{H}} 1.95 \mathrm{ppm}$ is assigned to $-\mathrm{CH}_{3}$ protons, and the resonance peak at $4.85 \mathrm{ppm}$ for $-\mathrm{CH}_{2}$ - protons. A slight shift in MCHMA- $\mathrm{C}_{14} \mathrm{MC}$ spectra was shown in Fig. 4b. The peak of the cyclohexyl group in MCHMA- $\mathrm{C}_{14} \mathrm{MC}$ shifts from 1.50 and $1.85 \mathrm{ppm}$ of the monomer to $1.61 \mathrm{ppm}$, the methylene group adjacent the cyclohexyl group and the chemical transposition of the methylene group connected to the ester group were shifted to $4.68 \mathrm{ppm}$. The shift is at $3.94 \mathrm{ppm}$, and the peak at $1.04 \mathrm{ppm}$ is the chemical shift of the hydrogen in the terminal methyl group of the long-chain alkyl group. The chemical shifts of the methylene group and the double bond in the remaining long-chain alkyl groups appear at $1.29 \mathrm{ppm}$. The spectrum of the copolymer without the $-\mathrm{CH}_{2}$ resonance peak occurred at 5.5-6.1 ppm. This feature also indicates that the copolymer has been successfully synthesized. The peak area integration, the feed ratio and the real ratio of MCHMA- $\mathrm{C}_{14} \mathrm{MC}$ shown in Table 2 according to ${ }^{1} \mathrm{H}$ NMR spectrum.

GPC analysis

Gel Permeation Chromatography (GPC) achieves the separation of polymer molecules according to the different permeability of different molecular weight substances in the chromatogram. In this study, the mobile phase consisted tetrahydrofuran and its speed was $1 \mathrm{ml} / \mathrm{min}$, polystyrene as the standard phase.

Generally speaking, the molecular weight of the PPDs is usually between 4000 and 100,000 g/mol, which can effectively be reducing the SP and CFPP of biodiesel ${ }^{[4]}$. The datas are listed in Table 3. Among them, the weight-average molecular weight $\left(\mathrm{M}_{\mathrm{w}}\right)$ ranges from $2.64 \times 10^{4}$ to $6.81 \times 10^{4}$ and the number average molecular weight $\left(\mathrm{M}_{\mathrm{n}}\right)$ ranges from $1.28 \times 10^{4}$ to $2.33 \times 10^{4}$, the dispersion coefficient $\left(\mathrm{M}_{\mathrm{w}} / \mathrm{M}_{\mathrm{n}}\right)$ refers to the molecular weight distribution. The width of $\mathrm{M}_{\mathrm{w}} / \mathrm{M}_{\mathrm{n}}$ ranges from 1.835 to 2.911 . Thus, these copolymers have a moderate degree of polymerization and are very suitable as PPDs for biodiesel.

\section{$\mathrm{SP}$ and CFPP}

Depressive effect of PPDs with various n-alkyl chain length

The SP and CFPP of untreated B20 were -14 and $-4 . \triangle \mathrm{SP}$ and $\triangle \mathrm{CFPP}$ are defined as an absolute value of the reduction of SP and CFPP before and after B20 dopped with MCHMA-R $\mathrm{RC}_{1}\left(\mathrm{R}_{1}=\mathrm{C}_{12}, \mathrm{C}_{14}, \mathrm{C}_{16}\right.$, $\mathrm{C}_{18}$ ). The depressive effect of MCHMA-R ${ }_{1} \mathrm{MC}$ on B20 was listed in Fig. 5.

As it can be seen from Fig. 5, MCHMA- $\mathrm{C}_{16} \mathrm{MC}$ and MCHMA- $\mathrm{C}_{18} \mathrm{MC}$ showed a low depressive effect with $\triangle \mathrm{SP}$ and $\triangle \mathrm{CFPP}$ were within the scope of $5-10{ }^{\circ} \mathrm{C}$ and $0-7{ }^{\circ} \mathrm{C}$, respectively. Whereas MCHMA-C ${ }_{12} \mathrm{MC}$ has the least effect on $\Delta \mathrm{SP}$ of $\mathrm{B} 20$, and even have a negative impact on the $\Delta \mathrm{CFPP}$, which exacerbating the cold flow properties of B20. Accordingly, not all PPDs can effectively improve the cold flow properties of B20. MCHMA- $\mathrm{C}_{14} \mathrm{MC}$ exhibited a better depressive effect, compared with MCHMA-C ${ }_{12} \mathrm{MC}$, MCHMA$\mathrm{C}_{16} \mathrm{MC}$, and MCHMA- $\mathrm{C}_{18} \mathrm{MC}$. With increasing addition of MCHMA- $\mathrm{C}_{14} \mathrm{MC}$, the overall trends of $\Delta \mathrm{SP}$ and $\triangle$ CFPP were continuously increased first, but it gradually decreased after it reach Max value. It shows that the optimum quantity of MCHMA- $\mathrm{C}_{14} \mathrm{MC}$ additive is $2000 \mathrm{ppm}$, the $\Delta \mathrm{SP}$ and $\Delta \mathrm{CFPP}$ reached the maximum of 25 and $18{ }^{\circ} \mathrm{C}$, respectively. The experiment results show that the depression of PPDs is closely related to the number of carbon. Only when the length of the n-alkyl chain of PPD is closer to the average carbon number of diesel fuel can it have a more effective depressive effect on SP and CFPP.

Depressive effect of PPDs with various molar ratios 
As is shown in the Fig. 6, different monomer ratios of MCHMA- $\mathrm{C}_{14} \mathrm{MC}$ have different effects on reducing depression effect of $\mathrm{B} 20$. As the proportion of $\mathrm{C}_{14} \mathrm{MC}$ monomer gradually increased, the overall depressive effect showed increases at first and then decrease. As you can see in the figures, when the monomer ratio was 1:7, the additive concentration is $2000 \mathrm{ppm}$, the optimal reduction of SP and CFPP was 25 and 18 , respectively. This also indicated that not all the ratios of PPD have a positive effect on B20. When the molar ratio of the monomer was 1:1 and traces of PPDs was added, the SP began to decrease, but there was almost no change in CFPP. Perhaps the most important reason is that the proportion of cyclohexyl monomers is higher to increase the spatial resistance in the $\mathrm{MCHMA}-\mathrm{C}_{14} \mathrm{MC}$ polymer. Thus, the rigidity and viscosity of MCHMA- $\mathrm{C}_{14} \mathrm{MC}$ increases, resulting in deterioration of $\mathrm{MCHMA}-\mathrm{C}_{14} \mathrm{MC}$ in $\mathrm{B} 20$. As the MCHMA monomer is gradually lowered, when the monomer molar ratio is 1: 9, the $\Delta \mathrm{SP}$ and $\Delta \mathrm{CFPP}$ of B20 are $20{ }^{\circ} \mathrm{C}$ and $16{ }^{\circ} \mathrm{C}$, respectively. However, the depression effect was worse than the monomer molar ratio of 1:7. The reason is that excessive alkyl side chains provided in PPDs, resulting in too much crystalline site, and wax crystals are easy to adhere to each other to form a structure similar to a three-dimensional network, thereby increasing the viscosity and decreasing the cold flow properties of B20.

\section{POM analysis}

The low-temperature polarized light microscope is considered to be an effective method for observing the morphological changes of biodiesel crystals with or without a polymer low-temperature flow improver. MCHMA$\mathrm{C}_{14} \mathrm{MC}$ was named PPD-1 to PPD-5 in different proportions (1:1, 1:3, 1:5, 1:7 and 1:9). The microscope images at $-20{ }^{\circ} \mathrm{C}$ of untreated B20, and B20 treated with 2000 ppm PPDs were shown in Fig. 7 .

When the temperature of $\mathrm{B} 20$ without additives was reduced to $-20{ }^{\circ} \mathrm{C}$, a large number of band-shaped crystals are formed, the volume grows, and the particle size becomes larger so that B20 loses fluidity (Fig. 7a). However, after the addition of PPDs, the degree of dispersion, quantity, and size of the wax crystal have changed significantly. As the molar ratio of MCHMA- ${ }_{14} \mathrm{MC}$ changed from 1:1 to 1:7 (Fig. 7b,e), the size of the crystals gradually decreased, and its dimension becomes much smaller than the untreated B20 (Fig. 7a). The long-chain alkyl of the copolymers wound be inserted and co-crystallized with the n-alkanes in B20, thereby the groups in PPDs will be adsorbed on the surface of the crystal and inhibited the growth and formation of large crystal. At the same time, a large number of crystallization sites were provided to improve the dispersion of wax crystals in $\mathrm{B} 20$. When the MCHMA- $\mathrm{C}_{14} \mathrm{MC}$ molar ratio was less than 1: 7, since the MCHMA has a higher molar ratio, the spatial block was increased and the viscosity was increased, resulting in the copolymer easier to reunite, thereby presenting large and irregular wax crystals, as shown in Fig. $7 \mathrm{~b}$,d. When the MCHMA- $\mathrm{C}_{14} \mathrm{MC}$ molar ratios exceeds 1:7, the high molar ratio of $\mathrm{C}_{14} \mathrm{MC}$ in the PPD will provide more crystalline sites, resulting in a smaller crystal in Fig. 7f. However, a large number of small crystals are particularly easy to stick together, thereby forming a larger crystalline network structure, resulting in a decrease in low temperature fluid performance. This is the same trend as the decrease in the SP and CFPP in Fig. 5.and Fig. 6.

DSC analysis

The energy change during the phase transformation of biodiesel is quantitatively analyzed by DSC. As shown in Fig. 8, the energy changes during crystallization of pure B20 and B20 with PPD-1, PPD-2, PPD-3, PPD-4, and PPD-5 were studied. The data analysis of these thermograms is shown in Table 4.

The peak starting temperature( $\left.\mathrm{T}_{\text {onset }}\right)$ of the DSC curve means the initial precipitation temperature of wax crystal in B20. The absolute value of solid-liquid phase change energy $(\Delta \mathrm{H})$ means the stability of the dispersion system in a wax crystal system. As shown in Fig. 8 and Table $4, \mathrm{~T}_{\text {onset }}$ and $\Delta \mathrm{H}$ of untreated B20 are -7.27 and $20.57 \mathrm{~J} / \mathrm{g}$. The wax crystal initial precipitation temperature of all $\mathrm{B} 20$ with MCHMA-C ${ }_{14} \mathrm{MC}$ addition was lower than untreated B20. This shown that the presence of MCHMA- $\mathrm{C}_{14} \mathrm{MC}$ can slow down its rate of precipitation temperature and inhibit the growth of the wax crystal. The absolute value of $\Delta \mathrm{H}$ of B20 after PPD-1, PPD-2, PPD-3, PPD-4, PPD-5 treatment was $19.84 \mathrm{~J} / \mathrm{g}, 19.66 \mathrm{~J} / \mathrm{g}, 18.45 \mathrm{~J} / \mathrm{g}, 18.02 \mathrm{~J} / \mathrm{g}$, $18.05 \mathrm{~J} / \mathrm{g}$ in turn. Hence, the $\Delta \mathrm{H}$ of B20 was the smallest after PPD-4 treatment, and B20 dispersion was the most stable. The results of DSC analysis are consistent with the changes in POM analysis. 


\section{Rheological measurements}

Viscosity is an important index to characterize the fluidity of B20 at low temperatures. Fig. 9 showed the viscosity changes of treated and untreated B20 at different temperatures. The viscosities of all B20 in the graph decreased as the temperature increased, regardless of whether it is PPD treated or not.When the temperature is higher than CFPP, the viscosity of B20 have barely budged before and after adding the additive. The viscosity of untreated B20 increased sharply as the temperature decreased. As shown in the graph, the viscosity of B20 treated with different proportions of MCHMA- $\mathrm{C}_{14} \mathrm{MC}$ was lower than that of untreated B20, and the viscosity of B20 treated with PPD-4 was the lowest.

The reason is that MCHMA- $\mathrm{C}_{14} \mathrm{MC}$ can provided a large quantity of crystallization sites to enhance the dispersibility of wax crystals in B20. Meanwhile the groups in PPDs will be adsorbed on the surface of the crystal and inhibited the growth and formation of large crystals, thus reducing the viscosity of B20. The results of this analysis are accordance with the data of DSC analysis and POM analysis.

Mechanism research

The possible working mechanism for improving the cold flow properties of untreated B20 and B20 treated with MCHMA- $\mathrm{C}_{14} \mathrm{MC}$ was shown in Fig. 10. B20 is a blend of BWCO and diesel oil. BWCO contains fatty acid methyl esters with different saturation, while diesel is composed of hydrocarbons such as nalkanes and branched-chain alkanes. In untreated B20, n-alkanes and fatty acid methyl esters tend to precipitated and formed wax crystals at low temperatures, and further aggregated to form three-dimensional network structures. As the temperature decreases, more and more crystals are gradually precipitated and scattered around the original crystals, resulting in the increasing number and size of crystals. In MCHMA$\mathrm{C}_{14} \mathrm{MC}$ treated $\mathrm{B} 20$, the non-polar long-chain alkyl group of MCHMA- $\mathrm{C}_{14} \mathrm{MC}$ was inserted into B20 and co-crystallized with the n-alkanes, thereby the groups in PPDs will be adsorbed on the surface of the crystal and suppressed the growth and formation of oversized crystals. At the same time, amount number of crystallization sites were provided to enhance the dispersibility of wax crystals in B20. On the other part, the cyclohexyl group of MCHMA- $\mathrm{C}_{14} \mathrm{MC}$ was adsorbed on the wax crystal surface, which causes some repulsion, promotes the uniform dispersion of crystal molecules in the oil phase, and further hinders the growth and aggregation of crystals. Therefore, the crystallization behavior and crystal morphology of crystals in B20 after MCHMA- $\mathrm{C}_{14} \mathrm{MC}$ treatment are modified. MCHMA- $\mathrm{C}_{14} \mathrm{MC}$ can effectively improve the cold flow properties of B20.

\section{Conclusion}

(1) The copolymers of methylcyclohexyl methacrylate and methacrylate with different carbon chain lengths and monomer ratios were synthesized by free radical polymerization and analyzed by FTIR, ${ }^{1} \mathrm{H}$ NMR, and GPC.

(2) When the ratio of MCHMA- $\mathrm{C}_{14} \mathrm{MC}$ monomer is 1:7, the pour point depressing effect is the best. When the polymer content was $2000 \mathrm{ppm}$, the CFPP and SP of B20 were reduced by 18 and 25 , respectively.

(3) POM, DSC, and rheological analysis show that MCHMA- $\mathrm{C}_{14} \mathrm{MC}$ binary copolymer as a PPD can change the morphology and size of wax crystals in B20, delay the initial precipitation temperature of wax crystals, and add the number of crystals, Reducing the volume of crystals and reducing the viscosity of B20. A high proportion of alkyl side chains provide a large number of crystallization sites for wax crystals, weaken the intermolecular forces of different crystals, change the crystal crystallization behavior, and inhibit crystal growth. At the same time, the wax crystals are evenly distributed in the B20 system, hence improving the cold flow characteristics of B20.

\section{Acknowledgments}

This work was supported from the National Natural Science Foundation of China (Project Number 22008155, 22075183, 21878188 and 21975161), Science and Technology Commission of Shanghai Municipality Project (Project Number 18090503800), Shuguang Program of Shanghai Education Development Foundation and 
Shanghai Municipal Education Commission (Project Number 18SG52), Chenguang Program of Shanghai Education Development Foundation and Shanghai Municipal Education Commission (Project Number 19CG69), the Talent Development Foundation of Shanghai (Project Number 2018034), Shanghai Gaofeng \& Gaoyuan Project for University Academic Program Development.

Nomenclature

$\mathrm{PPD}=$ pour point depressant

PPDs $=$ pour point depressants

MCHMA- $\mathrm{R}_{1} \mathrm{MC}=$ methcyclohexyl methacrylate-methacrylate copolymers

$\mathrm{CFPP}=$ cold filter plugging point

$\mathrm{SP}=$ solid point

$\mathrm{POM}=$ polarizing optical microscopy

$\mathrm{DSC}=$ differential scanning calorimetry

$\mathrm{BPO}=$ benzoyl peroxide

FTIR $=$ Fourier Transform Infrared

$\mathrm{GPC}=$ Gel Permeation Chromatography

Conflict of Interest

The authors declare that they have no conflict of interest.

References

Anwar, A.l.; Garforth, A. (2016) Challenges and opportunities of enhancing cold flow properties of biodiesel via heterogeneous catalysis. Fuel, 173:189-208.

Admiral, A.; Abdullah, M.K.; Ariffin, A. (2016) Evaluation of Emulsified Acrylate Polymer and its Pour Point Depressant Performance.Procedia Chemistry, 19 : 319-326.

ASTM D6371.(2017) Standard Test Method for Cold Filter Plugging Point of Diesel and Heating Fuels, West Conshohocken, PA: ASTM International.

ASTM D5949.(2016) Standard test method for pour point of petroleum products (automatic pressure pulsing method), West Conshohocken, PA: ASTM International.

ASTM D445.(2019) Standard test method for kinematic viscosity of transparent and opaque liquids (and calculation of dynamic viscosity), West Conshohocken, PA: ASTM International.

Daho, T.; Vaitilingom, G.; Ouiminga, S.K.; Piriou, B.; Zongo, A.S.; Ouoba, S.; Koulidiati, J. (2013) Influence of engine load and fuel droplet size on performance of a CI engine fueled with cottonseed oil and its blends with diesel fuel. Applied Energy, 111 : 1046-53.

Du, T.; Wang, S.; Liu, H.; Liu, J. (2013) Study on Commercial Pour Point Depressants Lowering Cold Filter Plugging Point for Daqing Diesel Fuels.Petroleum Science and Technology , 31 :1078-84

Eryilmaz, T.; Yesilyurt, M.K.; Cesur, C.; Gokdogan, O. (2016) Biodiesel production potential from oil seeds in Turkey. Renewable and Sustainable Energy Reviews , 58 : 842-51.

Eryilmaz, T.; Yesilyurt, M.K. (2016) Influence of blending ratio on the physicochemical properties of safflower oil methyl ester-safflower oil, safflower oil methyl ester-diesel and safflower oil-diesel.Renewable Energy , 95 : 233-47. 
Eryilmaz,T; Yesilyurt, M.K.; Gokdogan, O. (2015) Prediction of density of waste cooking oil biodiesel using artificial neural networks.Fresenius Environmental Bulletin, 24 : 1862-70.

Giraldo, S.Y.; Rios, L.A.; Suárez,N. (2013) Comparison of glycerol ketals, glycerol acetates and branched alcohol-derived fatty esters as cold-flow improvers for palm biodiesel. Fuel , 108: 709-714.

Gu, J.; Gao, Y.; Xu, X.; Wu, J.; Yu, L.; Xin, Z.; Sun, S. (2018) Biodiesel production from palm oil and mixed dimethyl/diethyl carbonate with controllable cold flow properties. Fuel , 216 : 781-786.

Gomes, L.C.; Rosas, DdO.; Chistone, R.C.; Zotin, F.M.Z.; de Araujo, Lucia R.Raddi; Zotina, José L. (2017) Hydroisomerization of n-hexadecane using $\mathrm{Pt} /$ alumina-Beta zeolite catalysts for producing renewable diesel with low pour point. Fuel, 209 : 521-528.

GB/T261.(2008) Standard Press of China, Determination of flash point-Pensky-Martens closed cup method . Beijing, China: Standard Press of China.

GB/T258. (2016) Standard Press of China, Standard test method for determination of acidity of light petroleum product. Beijing, China: Standard Press of China.

Lim, S.; Teong, L.K. (2010) Recent trends, opportunities and challenges of biodiesel in Malaysia: An overview. Renewable \& Sustainable Energy Reviews, 14:938-54.

Magalhães, A.M.S.; Pereira, E.; Meirelles, A.J.A.; Sampaio, K.A.; Maximo, G.J. (2019) Proposing blends for improving the cold flow properties of ethylic biodiesel. Fuel , 253 : 50-59.

Mao, J.; Liu, J.; Peng, Y.; Zhang, Z.; Zhao, J. (2018) Quadripolymers as viscosity reducers for heavy oil. Energy Fuels, 32 : 119-24.

Ma, P.; Xue, Y.; Zhao, W.; Lan, G.; Hang, Z.; Liu, F.; Han, S. (2015) Study on the performance mechanism of methacrylate pour point depressant in soybean biodiesel blends. Rsc Advances , 5 : 90144-9.

Monirul, I.M.; Kalam, M.A.; Masjuki, H.H.; Zulkifli, N.W.M.; Shahir, S.A.; Mosarof, M.H.; Ruhul, A.M. (2017) Influence of poly(methyl acrylate) additive on cold flow properties of coconut biodiesel blends and exhaust gas emissions. Renewable Energy , 101 : 702-12.

OliveiraLize, M.S.L.; Nunes, R.C.P.; Melo, I.C.; Ribeiro, Y.L.L.; Reis, L.G.; Dias, Júlio C.M.; uimarães,

Regina C.L.; Lucas, E.F. (2016) Evaluation of the correlation between wax type and structure/behavior of the pour point depressant. Fuel Processing Technology, 149: 268-74.

Rao, P.V.; Chary, D.P. (2018) Characteristics comparison of Biodiesel-Diesel Blend (B20) Fuel with Alcohol Additives. Int J Adv Eng Res Sci , 5 : 128-32.

Sharafutdinov, I.; Stratiev, D.; Shishkova, I.; Dinkov, R.; Batchvarov, A.; Petkov, P.; Rudnev, N. (2012) Cold flow properties and oxidation stability of blends of near zero sulfur diesel from Ural crude oil and FAME from different origin. Fuel, 96 : 556-567.

Su, B.; Wang, L.; Xue, Y.; Yan, S.; Han, S. (2021) Effect of Pour Point Depressants Combined with Dispersants on the Cold Flow Properties of Biodiesel-Diesel Blends. Journal of the American Oil Chemists Society , $98: 163-72$.

SH/T0604. (2000) Crude petroleum and petroleum productsdetermination of density-oscillating U-tube method. Beijing, China: Standard Press of China.

Toda, M.; Takagaki, A.; Okamura, M.; Kondo, J.N.; Hayashi, S.; Domen, K.; Hara, M. (2005) Green chemistry: biodiesel made with sugar catalyst.Nature, 38 :178.

Wang, J.; Zhao, W.; Ai,Y.; Chen, H.; Cao, L.; Han,S. (2015) Improving the fuel properties of biodiesel via complementary blending with diesel from direct coal liquefaction. RSC Adv. , 5 : 45575-81. 
Xue, Y.; Zhao, Z.; Xu, G.; Lian, X.; Yang, C.; Zhao, W.; Ma, P.; Lin, H.; Han, S. (2016) Effect of polyalpha-olefin pour point depressant on cold flow properties of waste cooking oil biodiesel blends. Fuel,184 :110-117.

Xu, G,; Xue, Y.; Zhao, Z.; Lian, X.; Lin, H.; Han, S. (2018) Influence of poly (methacrylate-co-maleic anhydride) pour point depressant with various pendants on low-temperature flowability of diesel fuel.Fuel, 216 : 898-907.

Zhou, M.; He, Y.; Lin, H.; Han, S. (2016) Effect of MC-MA polymer pour point depressants on the flow properties of biodiesel. Energy Sources Part A Recovery Utilization and Environmental Effects ,38 : 1962-8.

Zhou, M.; He, Y.; Chen, Y.; Yang, Y.; Lin, H.; Han, S. (2015) Synthesis and Evaluation of Terpolymers Consist of Methacrylates with Maleic Anhydride and Methacrylic Morpholine and Their Amine Compound as Pour Point Depressants in Diesel Fuels. Energy Fuels , 29 : 150824104944002.

Zhao, W.; Xue, Y.; Ma, P.; Ma, W.; Wang, J.; Lu, D.; Han, S. (2016) Improving the cold flow properties of high-proportional waste cooking oil biodiesel blends with mixed cold flow improvers. RSC Adv. , 6 :1336513370 .

Tables

Table 1. Fuel properties of diesel, biodiesel, and B20.

\begin{tabular}{lllll}
\hline Fuel properties & Methods & Diesel & Biodiesel & B20 \\
\hline Cold filter plugging point $\left({ }^{\circ} \mathrm{C}\right)$ & ASTM D6371 & -2 & 6 & -4 \\
Solid point $\left({ }^{\circ} \mathrm{C}\right)$ & ASTM D5949 & -13 & 5 & -14 \\
Kinematic viscosity at $40{ }^{\circ} \mathrm{C}\left(\mathrm{mm}^{2} / \mathrm{s}\right)$ & ASTM D445 & 3.526 & 4.03 & 3.05 \\
Flash point $\left({ }^{\circ} \mathrm{C}\right)$ & GB/T261 & 80 & 138 & 117 \\
Density at $20{ }^{\circ} \mathrm{C}\left(\mathrm{kg} / \mathrm{m}^{3}\right)$ & SH/T0604 & 810.6 & 863.3 & 845.0 \\
Acid value $(\mathrm{mg}$ of $\mathrm{KOH} / 100 \mathrm{ml})$ & GB/T258 & 1.75 & 0.44 & 0.26 \\
\hline
\end{tabular}

Table 2 The ratio of MCHMA- $\mathrm{C}_{14} \mathrm{MC}$

\begin{tabular}{lll}
\hline Copolymer & Feed ratio of MCHMA- $\mathrm{C}_{14} \mathrm{MC}$ & Real ratio of $\mathrm{MCHMA} \mathrm{C}_{14} \mathrm{MC}$ \\
\hline MCHMA-C $_{14} \mathrm{MC}$ & $1: 1$ & $1: 1.03$ \\
& $1: 3$ & $1: 2.9$ \\
& $1: 5$ & $1: 5.8$ \\
& $1: 7$ & $1: 6.99$ \\
& $1: 9$ & $1: 8.7$ \\
MCHMA-C $_{12} \mathrm{MC}$ & $1: 7$ & $1: 6.9$ \\
MCHMA-C $_{16} \mathrm{MC}$ & $1: 7$ & $1: 7.5$ \\
MCHMA-C $_{18} \mathrm{MC}$ & $1: 7$ & $1: 6.8$ \\
\hline
\end{tabular}

Table 3 The molecular weight of copolymers

\begin{tabular}{llll}
\hline Copolymers & $\mathrm{M}_{\mathrm{w}}{ }^{\mathrm{a}}$ & $\mathrm{M}_{\mathrm{n}}{ }^{\mathrm{b}}$ & $\mathrm{M}_{\mathrm{w}}{ }^{\mathrm{a}} / \mathrm{M}_{\mathrm{n}}{ }^{\mathrm{b}}$ \\
\hline MCHMA-C $_{14} \mathrm{MC}(1: 1)$ & 32166 & 17526 & 1.83533 \\
MCHMA-C $_{14} \mathrm{MC}(1: 3)$ & 38251 & 18405 & 2.07829 \\
MCHMA-C $_{14} \mathrm{MC}(1: 5)$ & 26466 & 12869 & 2.05657 \\
MCHMA-C $_{14} \mathrm{MC}(1: 7)$ & 68050 & 23380 & 2.91061 \\
MCHMA-C $_{14} \mathrm{MC}(1: 9)$ & 59005 & 22931 & 2.57315 \\
\hline
\end{tabular}


Note: $\mathrm{M}_{\mathrm{w}}{ }^{\mathrm{a}}=$ Weight-average molecular weight, $\mathrm{M}_{\mathrm{n}}{ }^{\mathrm{b}}=$ Number-average molecular weight.

Table 4 Data analysis of the DSC curves.

\begin{tabular}{lllll}
\hline Sample & $\mathrm{T}_{\text {onset }}()$ & $\mathrm{T}_{\text {peak }}()$ & $\mathrm{T}_{\text {endset }}()$ & $\Delta \mathrm{H}(\mathrm{J} / \mathrm{g})$ \\
\hline B20 & -7.274 & -8.925 & -59.476 & 20.57 \\
PPD-1 & -7.280 & -8.858 & -59.489 & 19.84 \\
PPD-2 & -7.282 & -8.239 & -59.445 & 19.66 \\
PPD-3 & -7.676 & -9.492 & -59.490 & 18.45 \\
PPD-4 & -7.773 & -9.662 & -59.481 & 18.02 \\
PPD-5 & -8.213 & -10.137 & -59.457 & 18.05 \\
\hline
\end{tabular}

Figure legends

Fig 1 Synthesis procedure for the preparation of monomers

Fig 2 Procedure for the synthesis of copolymers

Fig 3 FTIR spectra of $\mathrm{C}_{14} \mathrm{MC}$ (a), MCHMA (b) and MCHMA- $\mathrm{C}_{14} \mathrm{MC}$ (c).

Fig $4{ }^{1} \mathrm{H}$ NMR spectra of MCHMA (a) and MCHMA-C $14 \mathrm{MC}(\mathrm{b})$

Fig 5 Effects of MCHMA- $R_{1}$ MC copolymers on $\Delta$ SP and $\Delta$ CFPP of B20

Fig 6 Effect of MCHMA- $\mathrm{C}_{14} \mathrm{MC}$ copolymers with various monomer ratios on the $\Delta \mathrm{SP}$ and $\Delta \mathrm{CFPP}$ of $\mathrm{B} 20$

Fig 7 POM images at $-20{ }^{\circ} \mathrm{C}$ : (a) neat B20; (b) B20+PPD-1; (c) B20+PPD-2; (d) B20+PPD-3; (e) B20+PPD-4; (f) B20+PPD-5.

Fig 8 DSC thermogram of untreated B20 and B20 treated with different MCHMA- $\mathrm{C}_{14} \mathrm{MC}$ during cooling.

Fig 9 Viscosity-temperature curves of untreated B20 and B20 with different proportions of PPD added.

Fig 10 Possible mechanism of MCHMA- $\mathrm{C}_{14} \mathrm{MC}$ for improving the flowability of B20.

\section{Hosted file}

image1.emf available at https://authorea.com/users/443617/articles/543592-methcyclohexylmethacrylate-methacrylate-copolymers-an-effective-cold-flow-improver-for-the-biodieselblends

Fig 1

\section{Hosted file}

image2.emf available at https://authorea.com/users/443617/articles/543592-methcyclohexylmethacrylate-methacrylate-copolymers-an-effective-cold-flow-improver-for-the-biodieselblends

Fig 2 


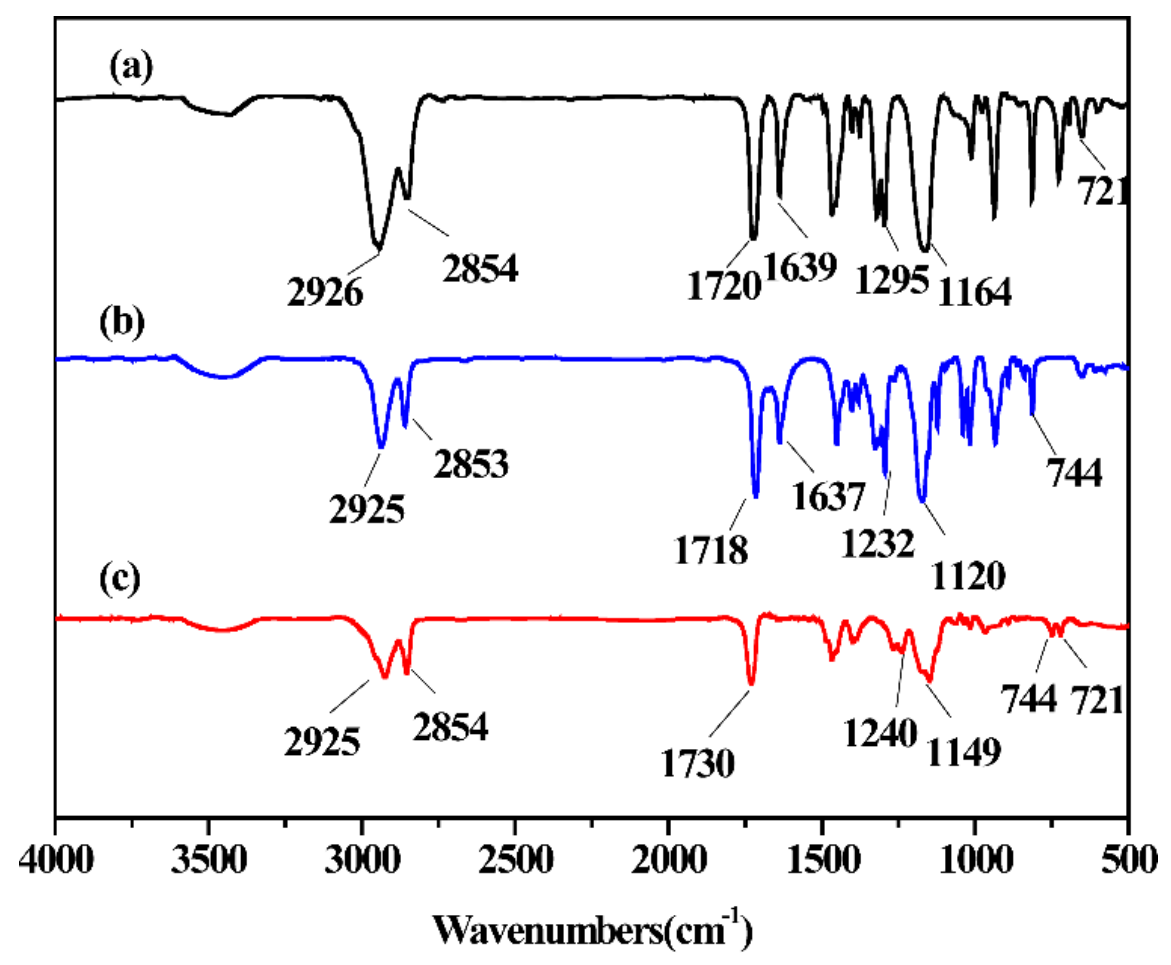

Fig 3

(a)

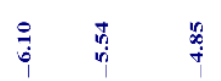

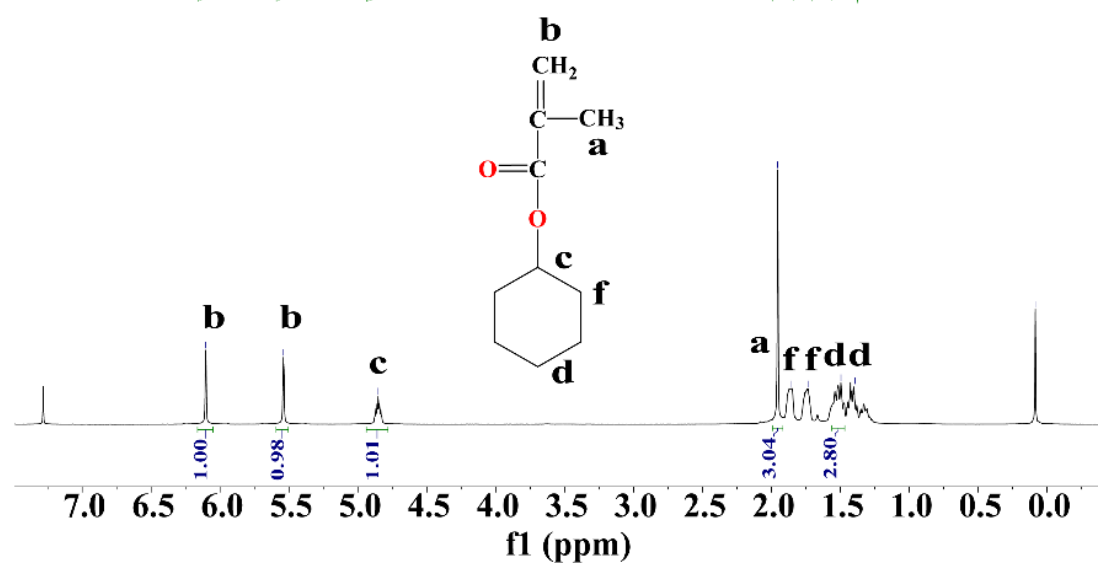


(b)

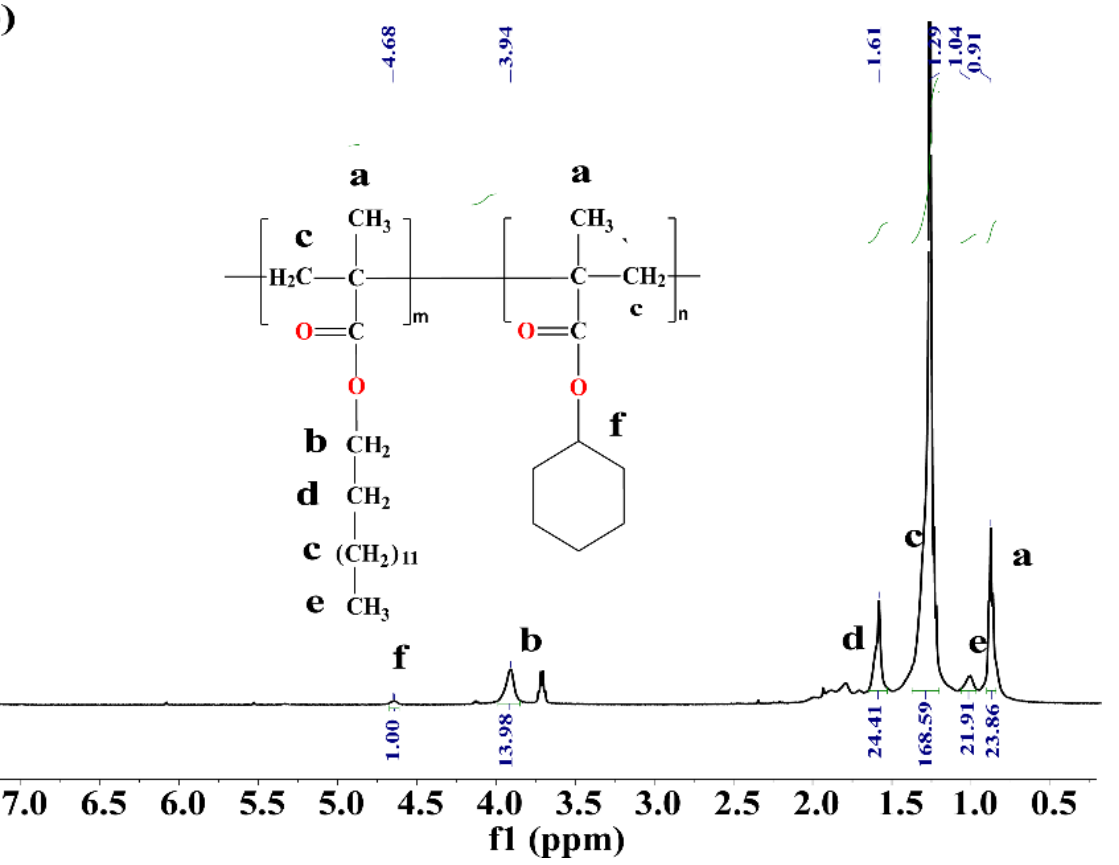

Fig 4
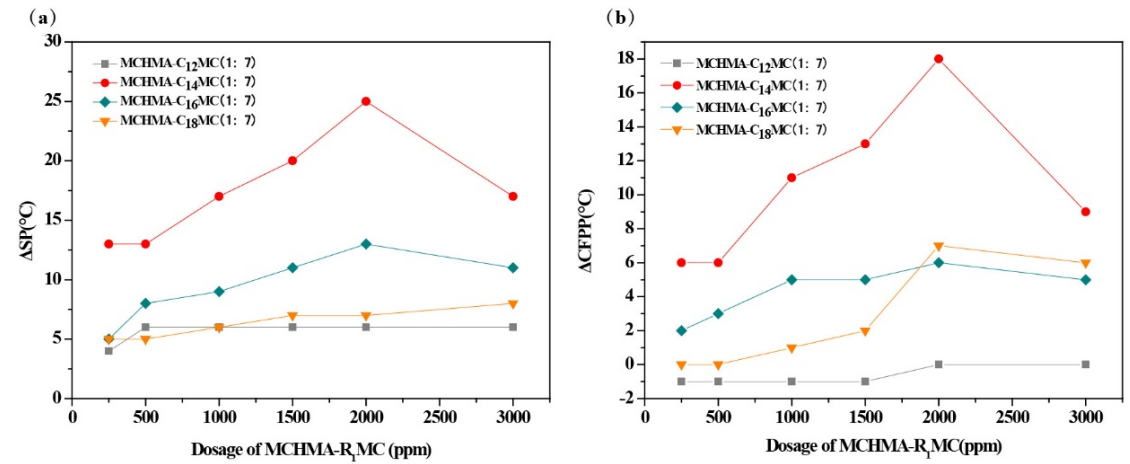

Fig 5
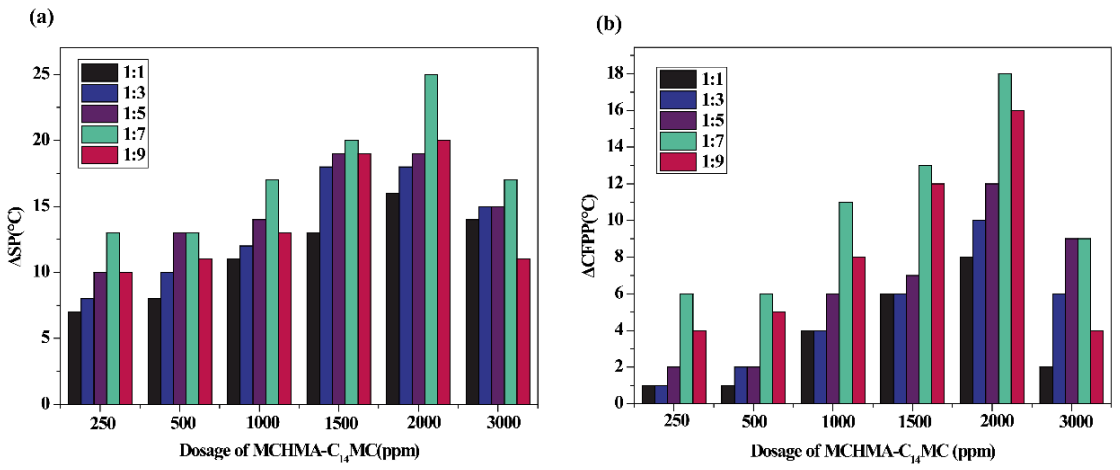
Fig 6
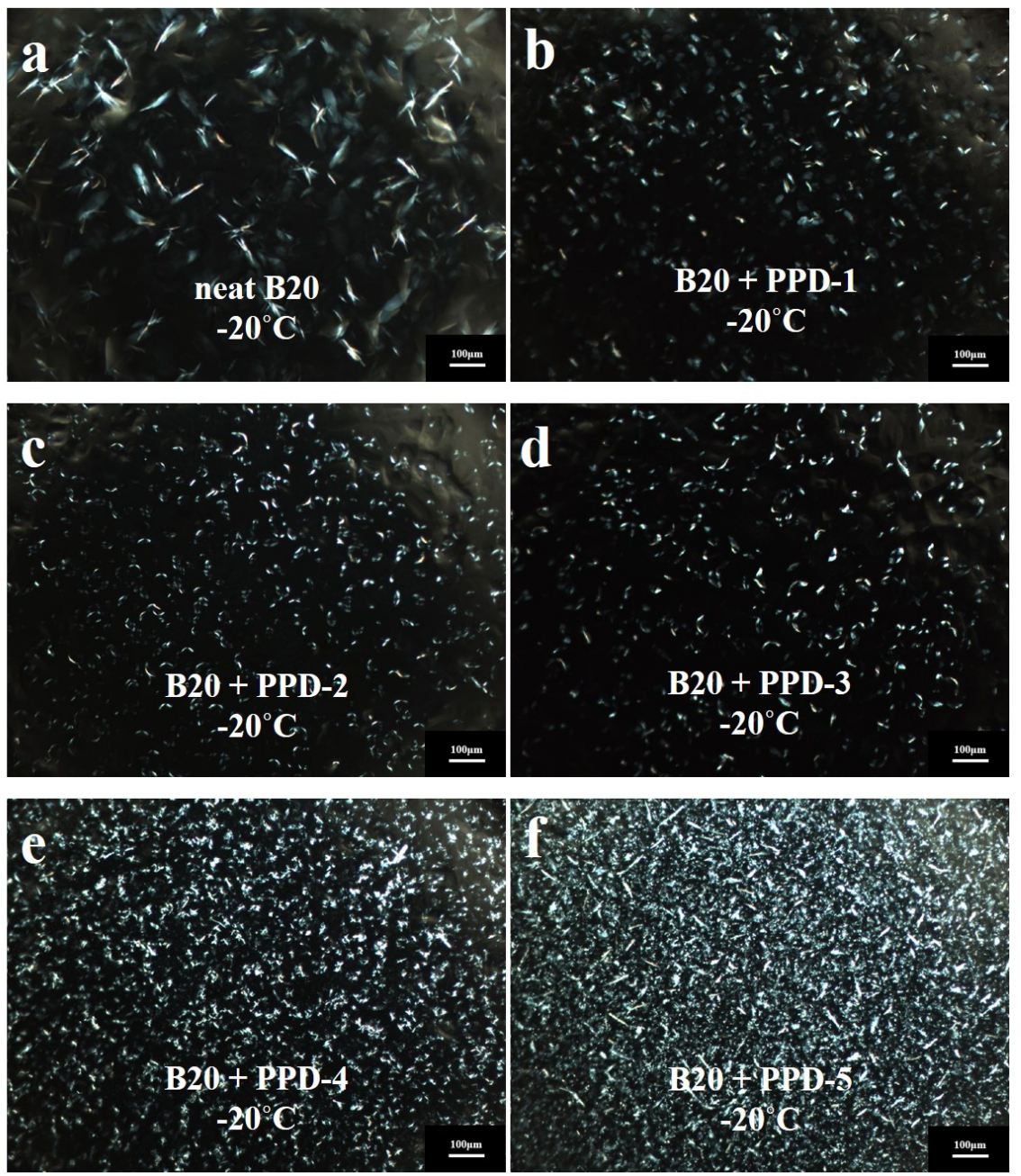

Fig 7 


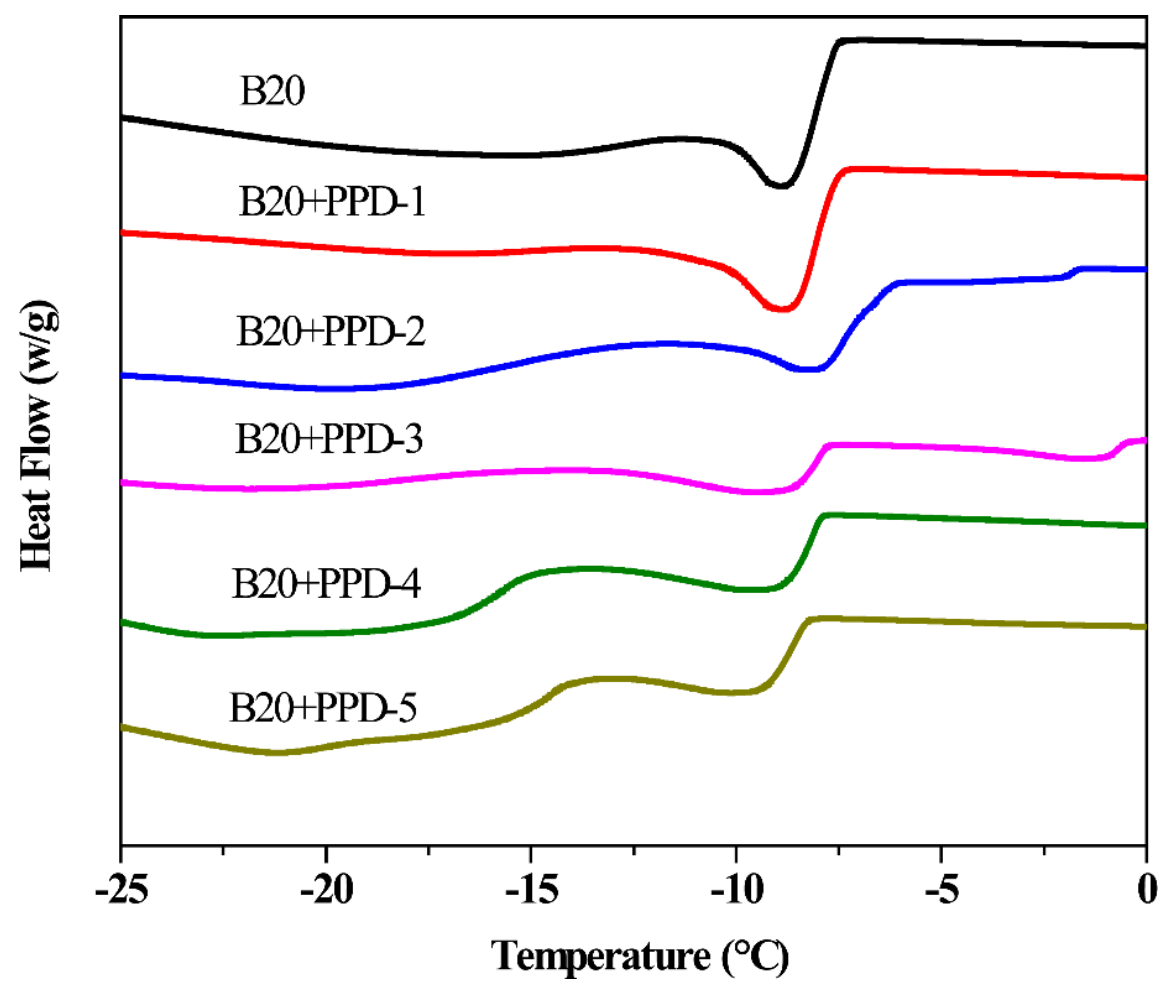

Fig 8

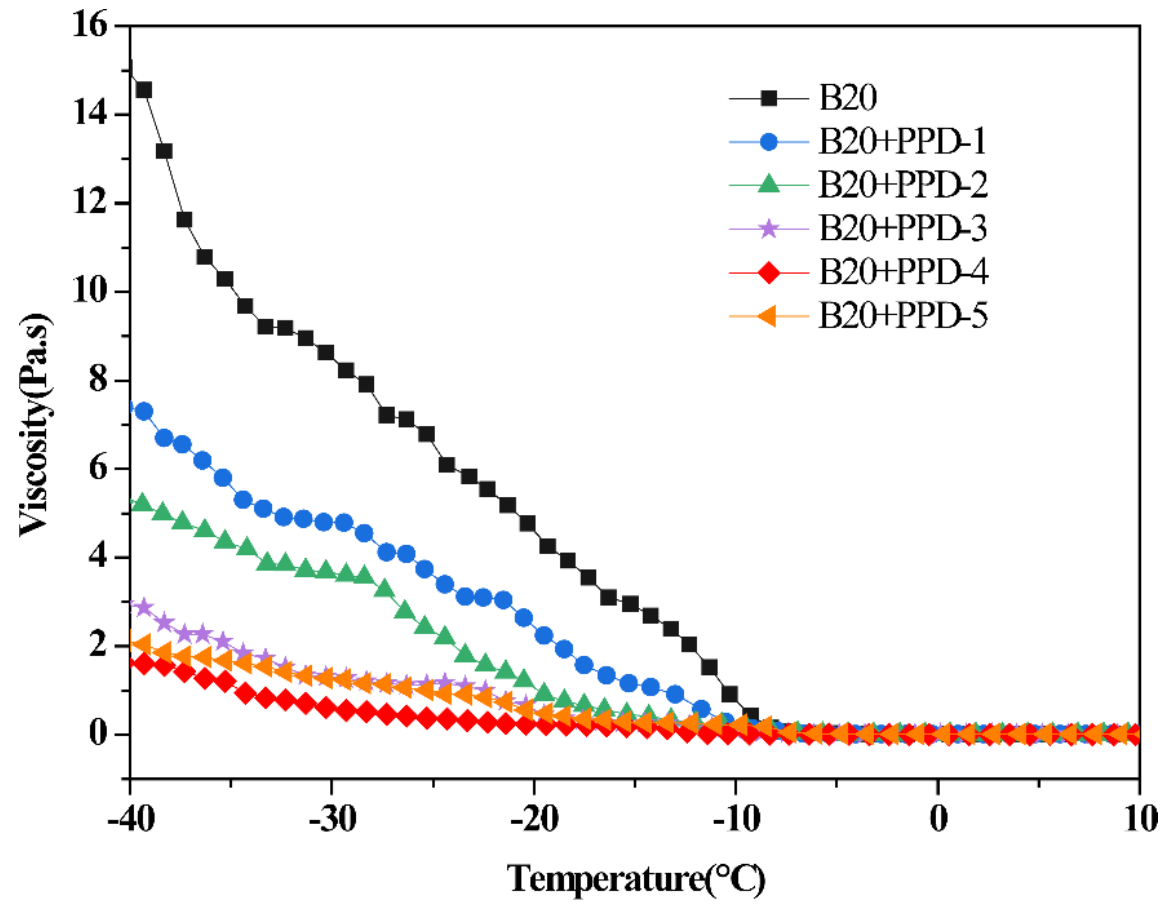

Fig 9 


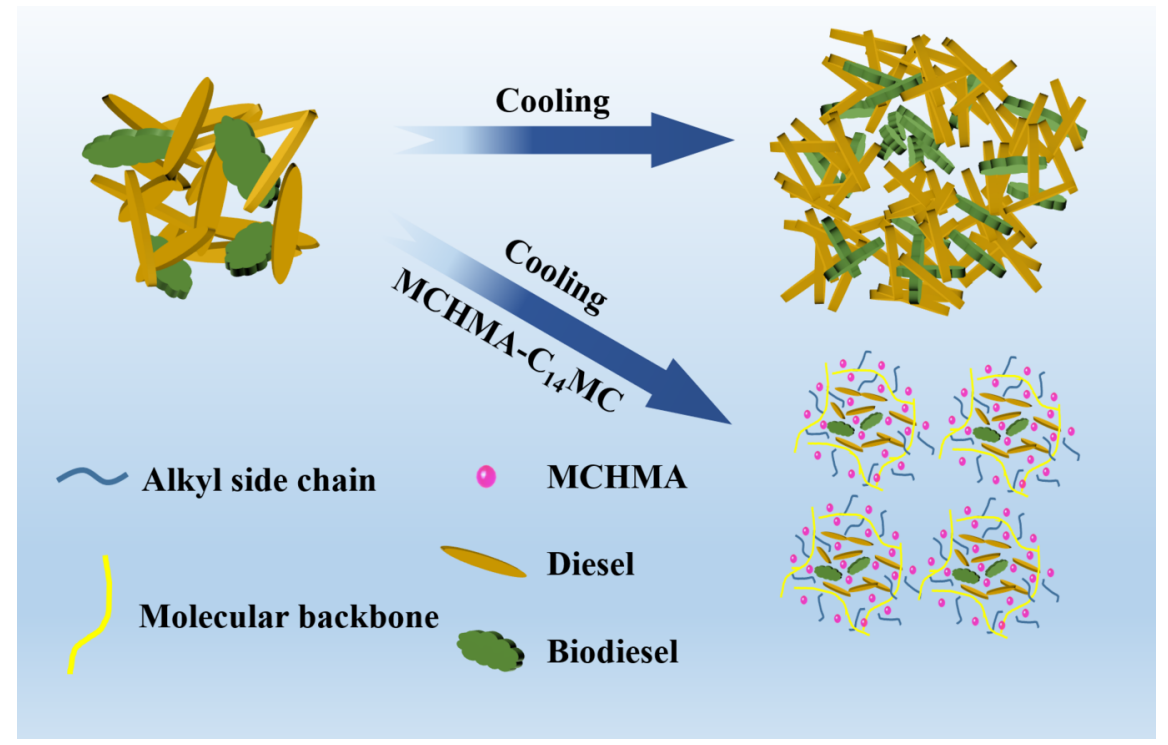

Fig 10 